\title{
Cardiac Magnetic Resonance with a Conditional Pacemaker at Three Tesla Field Strength
}

\author{
Ryan Mark Shulman 1,2,3, Maggie Moodley', \\ Manan Vaishnav ${ }^{4}$, Jeremy Wright ${ }^{5}$ \\ ${ }^{1}$ Queensland X-Ray, Gold Coast Private Hospital, Queensland, Australia \\ ${ }^{2}$ Departments of Medical Imaging, ${ }^{4}$ Cardiology, Gold Coast University Hospital, Southport, \\ Queensland, Australia \\ ${ }^{3}$ Griffith University, Southport, Queensland, Australia \\ ${ }^{5}$ Hearts First, Greenslopes Private Hospital, Queensland, Australia
}

CVIA 2018;2(1):28-30 / https://doi.org/10.22468/cvia.2017.00171

We would like to correct the names of authors as below;

Ryan Mark Shulman, Maggie Moodley, Manan Vaishnav, Jeremy Wright

In the original publication, all the authors' names were presented in reverse order.

(a) This is an Open Access article distributed under the terms of the Creative Commons Attribution Non-Commercial License (http://creativecommons.org/licenses/bync/4.0) which permits unrestricted non-commercial use, distribution, and reproduction in any medium, provided the original work is properly cited. 